\title{
Memory enhancement by multidomain group cognitive training in patients with Parkinson's disease and mild cognitive impairment: long-term effects of a multicenter randomized controlled trial
}

\author{
Nele Schmidt ${ }^{1,2} \cdot$ Inken Tödt $^{2} \cdot$ Daniela Berg ${ }^{2} \cdot$ Christian Schlenstedt $^{2} \cdot$ Ann-Kristin Folkerts $^{3} \cdot$ Anja Ophey $^{3}$. \\ Karina Dimenshteyn ${ }^{4}$ - Saskia Elben ${ }^{4} \cdot$ Lars Wojtecki $^{4} \cdot$ Inga Liepelt-Scarfone $^{5,6} \cdot$ Claudia Schulte $^{5} \cdot$ Patricia Sulzer $^{5}$. \\ Carsten Eggers $^{7,8} \cdot$ Elke Kalbe $^{3} \cdot$ Karsten Witt ${ }^{1,9}$
}

Received: 11 March 2021 / Revised: 12 April 2021 / Accepted: 15 April 2021 / Published online: 27 April 2021

(c) The Author(s) 2021

\begin{abstract}
Background Meta-analyses indicate positive effects of cognitive training (CT) in patients with Parkinson's disease (PD), however, most previous studies had small sample sizes and did not evaluate long-term follow-up. Therefore, a multicenter randomized controlled, single-blinded trial (Train-ParC study) was conducted to examine CT effects in PD patients with mild cognitive impairment (PD-MCI). Immediately after CT, an enhancement of executive functions was demonstrated. Here, we present the long-term results 6 and 12 months after CT.

Methods At baseline, 64 PD-MCI patients were randomized to a multidomain CT group $(n=33)$ or to a low-intensity physical activity training control group (PT) $(n=31)$. Both interventions included 90 min training sessions twice a week for 6 weeks. 54 patients completed the 6 months (CT: $n=28$, PT: $n=26)$ and 49 patients the 12 months follow-up assessment (CT: $n=25$, PT: $n=24)$. Primary study outcomes were memory and executive functioning composite scores. Mixed repeated measures ANOVAs, post-hoc $t$ tests and multiple regression analyses were conducted.

Results We found a significant time $\mathrm{x}$ group interaction effect for the memory composite score $\left(p=0.006, \eta^{2}=0.214\right)$, but not for the executive composite score $\left(p=0.967, \eta^{2}=0.002\right)$. Post-hoc $t$ tests revealed significant verbal and nonverbal memory improvements from pre-intervention to 6 months, but not to 12 months follow-up assessment in the CT group. No significant predictors were found for predicting memory improvement after CT.

Conclusions This study provides Class 1 evidence that multidomain CT enhances memory functioning in PD-MCI after 6 months but not after 12 months, whereas executive functioning did not change in the long-term.

Clinical trial registration German Clinical Trials Register (ID: DRKS00010186), 21.3.2016 (The study registration is outlined as retrospective due to an administrative delay. The first patient was enrolled three months after the registration process was started. A formal confirmation of this process from the German Clinical Trials Register can be obtained from the authors.)
\end{abstract}

Keywords Parkinson's disease $\cdot$ Mild cognitive impairment $\cdot$ Cognition $\cdot$ Cognitive training $\cdot$ Non-pharmacological intervention $\cdot$ Long-term effects

\section{Introduction}

Cognitive impairment is a common non-motor symptom in idiopathic Parkinson's disease (PD) with a prevalence of approximately $40 \%$ [1]. Since cognitive deficits have

Elke Kalbe and Karsten Witt shared senior authorship.

Karsten Witt

karsten.witt@uni-oldenburg.de

Extended author information available on the last page of the article a negative impact on patients' quality of life (QoL) [2], increase mortality [3] and so far only limited pharmacological treatment options are available $[4,5]$, there is a need for research in non-pharmacological interventions. Two meta-analyses showed positive effects of cognitive training (CT) in PD patients regarding executive functioning, working memory, memory, processing speed, or attention with small to medium effect sizes [6,7]. A review on nonpharmacological management of cognitive impairment in PD reported level B evidence for improving or maintaining memory, attention and working memory performance after 
CT [8], while another recent review on CT in PD patients with mild cognitive impairment (PD-MCI) and PD dementia did not find clear evidence that $\mathrm{CT}$ improves cognitive functioning [9]. However, the authors emphasize the low level of certainty due to small sample sizes, the heterogeneous study population concerning varying degrees of cognitive impairment, and the lack of studies reporting on long-term effectiveness. Moreover, little research has been done in the past to identify predictors of CT responsiveness in PD patients. Few previous studies systematically investigated a variety of sociodemographic, clinical, genetic, and neuropsychological factors [10-14], however, inconsistent results were reported for most predictors.

Our recently published multicenter randomized controlled trial (RCT) that is directly linked to the present study analyzed the short-term results of CT in PD-MCI patients compared to an active physical training control group (PT) [15]. In the CT group, an enhancement of executive functions (especially verbal fluency) and self-reported physical activity could be demonstrated while working memory improved in the PT group. In the memory domain, however, no significant training gains were found. Baseline cognitive levels, education, disease progression, and Apolipoprotein E4 (ApoE4) state were significant predictors for training responsiveness, indicating that vulnerable patients benefit the most from CT. Also, it could be shown that CT is feasible and safe for PD-MCI patients. Here, we report the long-term results of the study at 6 and 12 months follow-up assessments after CT. We aimed (1) to examine the long-term efficacy of CT regarding memory and executive functioning as well as further secondary cognitive and non-cognitive outcome parameters in PD-MCI, and (2) to identify predictors for training responsiveness at these follow-up time points.

\section{Methods}

\section{Study design}

The study is registered in the German Clinical Trials Register (ID: DRKS00010186) and was approved by the local ethic committees of all participating centers. All patients gave their informed consent in written form. Data were collected in four German university hospitals (Cologne, Duesseldorf, Tuebingen, Kiel) between July 2016 and May 2018. A priori sample size calculation focused on short-term training effects showed that an overall sample size of $n=80$ at baseline is necessary to achieve $80 \%$ power at a significance level at $p=0.05$ when considering a $10-15 \%$ drop-out rate. The participants were randomized to the $\mathrm{CT}$ or PT group and the persons who carried out the outcome investigations were blinded for intervention type. The patients were assessed pre- and post-intervention as well as 6 and 12 months after intervention, each assessment within a time frame of 4 weeks based on the first or last session of the intervention. All intervention sessions and diagnostic examinations were performed under regular antiparkinsonian medication. Data were entered in a secured online database system in pseudonymized form. Data monitoring was carried out by two members of another study site. For a detailed reporting on study design, randomization procedure and data management following the CONSORT statement, please see Kalbe et al. [15].

\section{Patients}

All patients were diagnosed with PD according to the UK Brain Bank criteria [16] and PD-MCI according to the Movement Disorders Society task force Level-II criteria [17] requiring impairment in at least two cognitive tests (operationalized as at least one standard deviation below the mean normative score). Further inclusion criteria were age between 50 and 80 years and a PD duration of at least three years with a stable medication within four weeks before screening procedure as well as subjective cognitive impairment as diagnosed using the Subjective Cognitive Impairment questionnaire [18] and/or objective cognitive impairment in the Montreal Cognitive Assessment [19] (cut-off $<26$ points). Exclusion criteria were a clinical PD dementia diagnosis according to the criteria of Emre et al. [20], impaired activities of daily living (ADL) according to the Pill Questionnaire [21] (impact on daily living is supposed when the patient cannot describe his or her regular medication and in case of doubt a caregiver confirms that he or she is no longer able to take the pills safely and reliably without supervision), and severe depression measured with the Beck Depression Inventory II [22] (cut-off $\geq 20$ points, range $0-63$ points, higher scores indicate more severe signs and symptoms of depression). In an anamnestic interview, the following exclusion criteria were evaluated: suicide tendency, severe comorbidities, severe fatigue, prominent impulse control disorder or dopamine dysregulation syndrome, acute psychosis or psychotic episode in the last six months, dementia medication, participation in other treatment studies within the last two months, pregnancy, or deep brain stimulation.

\section{Interventions}

As CT, the NEUROvitalis program [23] was conducted. In this standardized training program, executive functions, memory, attention, and visuocognition are trained by group tasks, activity games, individual exercises, and homework. Furthermore, it contains psychoeducative elements, e.g. explaining cognitive functions and strategies to enhance these functions. Two sessions of the original 
version of the program were modified in consideration of the characteristic cognitive profile of PD patients. More precisely, two memory sessions were replaced by sessions focusing on executive functions and visuocognition. The modified program was recently published as NEUROvitalis Parkinson [24]. The PT group received a low-intensity physical activity program which aimed to improve motor function but not cognition. Each session included warm-up exercises, specific exercises focusing on stretching, flexibility, loosening up, or relaxation, psychoeducation, and homework. Both training programs were conducted in groups with three to five patients and included two 90 min sessions a week over a total of six weeks. As part of CT and PT, patients were encouraged to stimulate themselves cognitively and physically after the end of the training phase, but no new training sessions or exercises were conducted until the follow-up assessments. For further details of the study interventions, we refer to Supplementary Table 1 in the article by Kalbe et al. [15].

\section{Outcomes}

Primary study outcomes were (i) a composite score for memory and (ii) a composite score for executive functions, both defined as averaged $\mathrm{z}$-scores of the respective cognitive test parameters. Secondary outcomes were composite scores for attention, working memory, visuocognition, and language, as well as single test results for ADL, self-reported physical activity, depression, QoL, self-experienced attention deficits, motor impairment, and freezing of gait. The Diagnostic Tests used were the following:

- Memory: California Verbal Learning Test (CVLT) [25]-total score trials 1-5 and long delay free recall II, Rey-Osterrieth Complex Figure Test (ROCFT) [26]— delayed recall.

- Executive functions: Regensburger word fluency tests [27] - phonemic and semantic word fluency, modified card sorting test [28]—-ategories completed, Behav-

Table 1 Sociodemographic and clinical baseline characteristics of the PD-MCI subgroups that are included in the 6 respective 12 months follow-up analyses

\begin{tabular}{|c|c|c|c|c|c|c|}
\hline & \multicolumn{3}{|l|}{6 months follow-up } & \multicolumn{3}{|c|}{12 months follow-up } \\
\hline & $\begin{array}{l}\text { Cognitive training } \\
(n=28)\end{array}$ & $\begin{array}{l}\text { Physical training } \\
(n=26)\end{array}$ & $p$ & $\begin{array}{l}\text { Cognitive training } \\
(n=25)\end{array}$ & $\begin{array}{l}\text { Physical training } \\
(n=24)\end{array}$ & $p$ \\
\hline Age (years) & $67.18 \pm 7.01$ & $67.50 \pm 8.71$ & $0.881^{\mathrm{a}}$ & $67.04 \pm 6.63$ & $67.08 \pm 8.85$ & $0.985^{\mathrm{a}}$ \\
\hline \multicolumn{7}{|l|}{ Sex } \\
\hline Male $(\%)$ & $21(75 \%)$ & $15(57.7 \%)$ & $0.250^{\mathrm{c}}$ & $19(76 \%)$ & $14(58.3 \%)$ & $0.232^{\mathrm{c}}$ \\
\hline Female $(\%)$ & $7(25 \%)$ & $11(42.3 \%)$ & & $6(24 \%)$ & $10(41.7 \%)$ & \\
\hline Years of education & $13.43 \pm 3.84$ & $13.96 \pm 3.33$ & $0.868^{\mathrm{b}}$ & $13.20 \pm 3.74$ & $13.92 \pm 3.20$ & $0.769^{\mathrm{b}}$ \\
\hline Age of PD symptom onset (years) & $58.11 \pm 8.61$ & $59.35 \pm 9.04$ & $0.613^{\mathrm{a}}$ & $57.92 \pm 7.60$ & $59.25 \pm 9.36$ & $0.591^{\mathrm{a}}$ \\
\hline Age at PD diagnosis (years) & $59.29 \pm 8.87$ & $59.96 \pm 9.11$ & $0.784^{\mathrm{a}}$ & $59.12 \pm 8.07$ & $59.88 \pm 9.15$ & $0.764^{\mathrm{a}}$ \\
\hline PD duration (months) & $93.07 \pm 66.32$ & $89.54 \pm 44.88$ & $0.917^{\mathrm{b}}$ & $93.52 \pm 68.0$ & $85.67 \pm 44.53$ & $0.772^{\mathrm{b}}$ \\
\hline \multicolumn{7}{|l|}{ Hoehn and Yahr stage } \\
\hline $1(\%)$ & $2(7.1)$ & $6(23.1)$ & $0.113^{\mathrm{d}}$ & $2(8.0)$ & $5(20.8)$ & $0.273^{\mathrm{d}}$ \\
\hline $2(\%)$ & $16(57.1)$ & $17(65.4)$ & & $15(60.0)$ & $16(66.7)$ & \\
\hline $3(\%)$ & $9(32.1)$ & $3(11.5)$ & & $7(28.0)$ & $3(12.5)$ & \\
\hline $4(\%)$ & $1(3.6)$ & 0 & & $1(4.0)$ & 0 & \\
\hline $5(\%)$ & 0 & 0 & & 0 & 0 & \\
\hline UPDRS-III & $25.43 \pm 13.26$ & $25.08 \pm 12.80$ & $0.931^{\mathrm{b}}$ & $25.04 \pm 12.34$ & $26.21 \pm 12.68$ & $0.681^{\mathrm{b}}$ \\
\hline LEDD & $890.80 \pm 519.80$ & $739.58 \pm 411.85$ & $0.411^{b}$ & $935.22 \pm 530.77$ & $739.92 \pm 425.73$ & $0.250^{\mathrm{b}}$ \\
\hline ApoE4 carriers & $5(17.9 \%)$ & $3(11.5 \%)$ & $0.711^{\mathrm{d}}$ & $4(16 \%)$ & $3(12.5 \%)$ & $1.000^{\mathrm{d}}$ \\
\hline BDI-II & $8.43 \pm 5.65$ & $7.28 \pm 4.11$ & $0.616^{\mathrm{b}}$ & $8.28 \pm 5.76$ & $7.57 \pm 4.17$ & $0.868^{\mathrm{b}}$ \\
\hline MoCA & $25.0 \pm 2.22$ & $24.23 \pm 3.15$ & $0.340^{\mathrm{b}}$ & $25.08 \pm 2.08$ & $24.13 \pm 3.26$ & $0.266^{\mathrm{b}}$ \\
\hline
\end{tabular}

Results are given in mean \pm standard deviation

$B D I$ Beck Depression Inventory, LEDD Levodopa equivalent daily dose, MoCA Montreal Cognitive Assessment, $P D$ Parkinson's Disease, UPDRS Unified Parkinson's Disease Rating Scale

${ }^{\mathrm{a}} t$ test

${ }^{\mathrm{b}}$ Mann-Whitney $U$ test

${ }^{c} \chi^{2}$ test

${ }^{\mathrm{d}}$ Fisher's exact test 
ioural Assessment of the Dysexecutive Syndrome [29] Key Search test.

- Attention: d2-R [30]—errors and concentration performance.

- Working memory: Wechsler Adult Intelligence Scale III [31] -letter-number sequencing and digit span backwards.

- Visuocognition: ROCFT—copy, Benton Judgment of Line Orientation [32].

- Language: Consortium to Establish a Registry for Alzheimer's Disease [33]—Boston Naming Test, Aphasia Check List [34]—speech comprehension.

- ADL: Bayer Activities of Daily Living Scale [35].

- Depression: Beck Depression Inventory II [22].

- Self-reported physical activity: Physical Activity Scale for the Elderly [36].

- Quality of Life: Parkinson's Disease Questionnaire 39 [37].

- Self-experienced attention deficits: Self-perceived deficits in attention questionnaire [38].

- Motor impairment: Unified Parkinson's Disease Rating Scale Part III (UPDRS III) [39].

- Freezing of gait: Freezing of Gait Questionnaire [40].

Parallel test versions were used if available. Neuropsychological assessments were conducted by trained psychologists, neurological tests were carried out by neurologists, physicians in neurological training, or PD nurses.

\section{Statistical analysis}

Data analyses were carried out using SPSS Statistics for Windows, Version 25.0 (Armonk, NY: IBM Corp). To investigate long-term effects of the $\mathrm{CT}$ group in comparison to PT, $3 \times 2$ (time $\times$ group) mixed repeated measures analyses of variances (ANOVA) were computed for primary and secondary outcome variables. An effect was considered significant at $p \leq 0.05$. As we used two primary outcome scores, we used Bonferroni correction for multiple testing and therefore considered an effect as significant at $p \leq 0.025$. Due to the exploratory character, no alpha-correction was applied for the secondary outcome analyses. Partial eta square $\left(\eta^{2}\right)$ is reported as effect size, indicating small effects from $\eta^{2}=0.01$ to $\eta^{2} \leq 0.06$, medium effects from $\eta^{2}>0.06$ to $\eta^{2}<0.14$, and large effects from $\eta^{2} \geq 0.14$ [41]. To avoid the risk of drop-out associated bias, we report the results of a per-protocol (PP) approach as well as of an intention-to-treat (ITT) approach for the ANOVAs. For the PP approach, only patients who completed the respective follow-up assessment were included in the analyses; for the ITT approach, missing data were imputed using the Last Observation Carried Forward (LOCF) method.
In case of a significant time $\mathrm{x}$ group interaction effect, test-specific post-hoc analyses were calculated to examine direction and temporal course of the effect. For this purpose, change scores were computed by subtracting baseline scores from 6 and 12 months follow-up scores, and tested for normal distribution using the Shapiro-Wilk test. Afterwards, change score differences between the intervention groups were compared with independent samples $t$ tests or Mann-Whitney $U$ tests, respectively. Moreover, paired $t$ tests for dependent samples, respectively, Wilcoxon tests were computed to detect significant mean score changes over time within both groups. Post-hoc significance levels were Bonferroni corrected for the number of cognitive tests within the respective domain.

Furthermore, we examined possible predictors of intervention responsiveness. Intervention responsiveness was operationalized by the change scores (differences between baseline level of the respective cognitive outcome score and the performance at follow-up assessment). Therefore, multiple linear regression analyses were performed for the 6 months as well as for the 12 months change scores. Concerning the training's specificity, the analyses were computed for both intervention groups. Following studies with healthy older adults and PD-MCI patients [42-49], we included as predictors the baseline level of the respective outcome variable, age, sex, education level, and ApoE4 status. Regarding PD characteristics, we added UPDRS III and levodopa equivalent daily dose (LEDD) as possible predictors what is in line with Kalbe et al. [15].

\section{Results}

\section{Dropout analysis}

Initially, 76 patients were screened for eligibility and after pretest 64 patients were randomly allocated to the CT group $(n=33)$ or PT $(n=31)$, respectively. The dropout rate during the intervention phase was $4.7 \%$ (CT: $n=2$, PT: $n=1)$. Out of the 61 patients who completed the pre- and post-intervention assessments, 54 patients completed the 6 months (CT: $n=28$, PT: $n=26$ ) and 49 patients completed the 12 months follow-up assessment (CT: $n=25$, PT: $n=24$ ). Dropout rates were $11.5 \%$ from baseline to 6 months followup and $9.3 \%$ from 6 to 12 months follow-up. Reasons for dropout were illness other than PD that made further participation impossible (CT: $n=2$, PT: $n=2$ ), loss of contact (CT: $n=1$, PT: $n=3$ ), patients' wish to stop participation (CT: $n=2$, PT: $n=1$ ), and deep brain stimulation (CT: $n=1$ ), see also Supplementary Fig. 1 (online resource). Drop-out patients did not significantly differ from patients who completed the study in terms of age ( $p=0.281$, Mann-Whitney $U$ test $)$, sex ( $p=0.223$, Fisher's exact test), intervention 
group ( $p=1.000$, Fisher's exact test), and motor impairment ( $p=0.409$, Mann-Whitney $U$ test $)$.

\section{Comparability between groups}

Sociodemographic and clinical baseline characteristics of the subgroups included in the 6 and 12 months follow-up analyses can be seen in Table 1 . The intervention groups were comparable with regard to age, sex distribution, education, disease onset, disease duration, severity of motor symptoms, LEDD, ApoE4 state, and depression. Further, we checked for comparability between groups concerning the training participation. Patients included in the 6 months follow-up analysis participated in 11 of the 12 training sessions (median; CT range: 8-12, PT range: 9-11) independent of group affiliation $\left(\chi^{2}=5.333 ; p=0.255\right)$. For the 12 months follow-up groups median and range did not change $\left(\chi^{2}=2.536 ; p=0.638\right)$.

\section{Long-term effects of the cognitive training}

Table 2 presents the results of the training effects analyses. Regarding the primary outcome variables, time $\times$ group interaction was significant for memory composite score (PP: $p=0.006, \eta^{2}=0.214$; ITT: $p=0.023, \eta^{2}=0.123$ ), indicating a medium effect size favouring the $\mathrm{CT}$ group. Interaction effects for the executive functions composite score as well as for all secondary cognitive and non-cognitive outcomes did not reach significance. Post-hoc tests showed that change scores are significantly higher in the CT group than in the PT group at 6 months follow-up for CVLT total score $(p=0.011)$, and ROCFT delayed recall $(p=0.014)$, however, there were no significant change score differences at 12 months follow-up assessment (Table 3). Moreover, paired $t$ tests showed significantly better test results at 6 months follow-up compared to baseline assessment for CVLT total score $(p<0.001)$, and ROCFT delayed recall $(p=0.002)$ in the CT group. No significant differences were found between pre-intervention and 12 months follow-up assessment. In the PT group, there were significant differences between baseline and 6 as well as 12 months follow-up assessments for CVLT delayed recall ( $p=0.001$ respective $p=0.013)$ with better test results at the follow-up assessments. All significant results indicate an improvement over time. Between 6 and 12 months follow-up, there were no significant memory changes in either group. The results are presented in Table 4. Figure 1 illustrates the course of the memory scores in both groups.

\section{Prediction of long-term effects}

Significant models for predicting change scores of the CT group were found within the executive function, visuocognition and language domains as well as for $\mathrm{QoL}$ and motor function at 6 months follow-up $\left(0.374 \leq R^{2}\right.$ adj $\left.\leq 0.713\right)$. There was no significant regression model for the prediction of training responsiveness in the memory domain after 6 months. At 12 months follow-up, significant predictive models were found within the memory, executive functions, attention, working memory, visuocognition, and language domains as well as for self-reported physical activity and QoL $\left(0.337 \leq R_{\text {adj }}^{2} \leq 0.651\right)$. A lower baseline level in the respective outcome variable significantly predicted training gains in almost all significant regression models, the only exceptions were the QoL models. Additionally, higher respective lower age, female respective male sex, higher education level, lower baseline motor status and LEDD, and positive respective negative ApoE4 status were significant predictors for training gains in some secondary outcome parameters after CT. For the PT group, significant regression models were found for the prediction of memory, executive, visuocognitive, language, motor function and ADL change scores after 6 or 12 months $\left(0.374 \leq R^{2}{ }_{\text {adj }} \leq 0.961\right)$ with lower baseline levels as significant predictors for training responsiveness in all cases, and higher age, male sex, higher education level, lower baseline UPDRS III score, and higher baseline LEDD as significant predictors in few single variables. All significant regression models are presented in Supplementary Tables 1 and 2 (online resource).

\section{Discussion}

We report the long-term results of a multicenter RCT assessing the effects of CT in comparison to an active control training in PD-MCI. In our previous report [15], we could show that $\mathrm{CT}$ is feasible and safe for PD patients. Furthermore, we provided evidence for an enhancement of executive functions shortly after CT compared to PT. In the present study, we extended these results by demonstrating training gains of the CT group in the memory domain after 6 months. The main results for 6 and 12 months follow-up assessments were: (i) CT enhanced memory functions after 6 months while there was no positive effect after 12 months, (ii) there were no significant improvements of executive functions or other cognitive and non-cognitive parameters at 6 and 12 months follow-up assessments, (iii) training gains in the memory domain cannot be predicted by means of baseline score, age, sex, education, LEDD, or ApoE4 state. These results provide Class 1 evidence for memory enhancement following CT after 6 months given the multi-center randomized and single-blinded design.

We found a significant interaction effect for the memory composite score indicating an enhancement of memory performance in the CT group. This effect remained after imputing missing data. Post-hoc analyses showed that the 


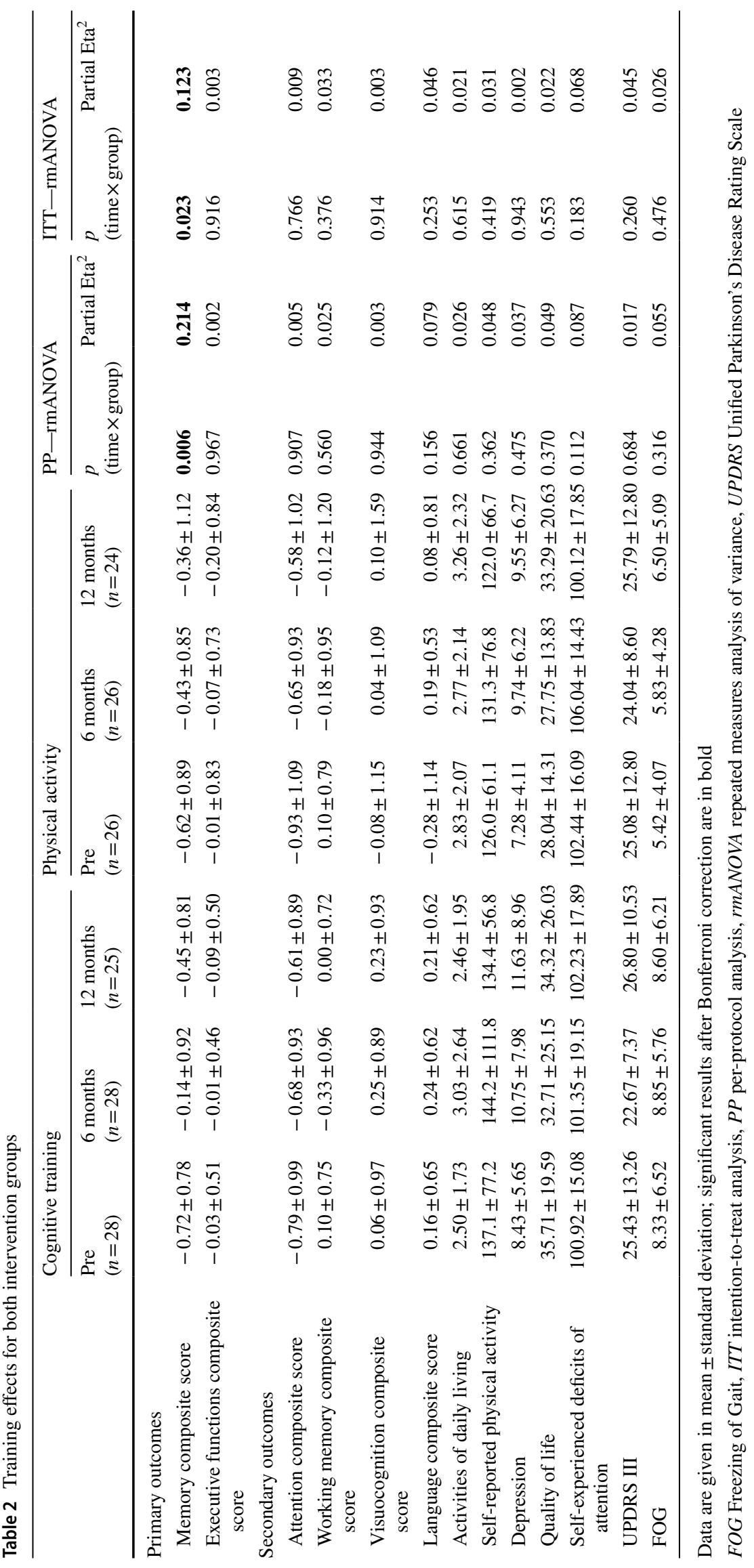


Table 36 and 12 months memory change score differences between cognitive training and physical activity group

\begin{tabular}{|c|c|c|c|c|c|c|c|c|}
\hline & \multicolumn{2}{|c|}{6 months change score } & \multicolumn{2}{|l|}{$t$ test } & \multicolumn{2}{|c|}{12 months change score } & \multicolumn{2}{|l|}{$t$ test } \\
\hline & $\begin{array}{l}\text { Cognitive } \\
\text { training }\end{array}$ & Physical activity & $T$ & $p$ & $\begin{array}{l}\text { Cognitive } \\
\text { training }\end{array}$ & Physical activity & $T$ & $p$ \\
\hline CVLT total score trials $1-5$ & $1.01 \pm 1.02$ & $0.24 \pm 0.94$ & $-2.541^{a}$ & $0.011^{\mathrm{a}}$ & $0.51 \pm 1.31$ & $0.46 \pm 1.56$ & $-0.460^{\mathrm{a}}$ & $0.645^{\mathrm{a}}$ \\
\hline $\begin{array}{l}\text { CVLT long delay free recall } \\
\text { II }\end{array}$ & $0.41 \pm 0.85$ & $0.53 \pm 0.58$ & -0.616 & 0.540 & $0.19 \pm 1.07$ & $0.53 \pm 0.97$ & -1.170 & 0.248 \\
\hline ROCFT delayed recall & $0.57 \pm 0.84$ & $-0.03 \pm 0.84$ & 2.540 & 0.014 & $0.32 \pm 0.75$ & $-0.07 \pm 1.05$ & 1.488 & 0.144 \\
\hline
\end{tabular}

6 months change scores are defined as $\Delta 6$ months follow-up-pre-intervention $z$-scores; 12 months change scores are defined as $\Delta 12$ months follow-up_-pretest $z$-scores; data are given in mean \pm standard deviation, significant results after Bonferroni correction are in bold

CVLT California Verbal Learning Test, ROCFT Rey-Osterrieth Complex Figure Test

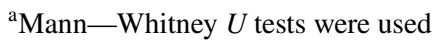

Table 4 Memory test results before intervention and at 6 and 12 months follow-up assessment in both intervention groups

\begin{tabular}{|c|c|c|c|c|c|c|c|c|c|}
\hline & \multirow[t]{2}{*}{ Pre-intervention } & \multirow[t]{2}{*}{6 months } & \multirow[t]{2}{*}{12 months } & \multicolumn{2}{|c|}{$\begin{array}{l}\text { pre-intervention vs. } \\
6 \text { months }\end{array}$} & \multicolumn{2}{|c|}{$\begin{array}{l}\text { pre-intervention } \\
\text { vs. } 12 \text { months }\end{array}$} & \multicolumn{2}{|c|}{$\begin{array}{l}6 \text { months vs. } \\
12 \text { months }\end{array}$} \\
\hline & & & & $T / Z$ & $p$ & $T / Z$ & $p$ & $T / Z$ & $p$ \\
\hline Cognitive training & $n=28$ & $n=28$ & $n=26$ & & & & & & \\
\hline CVLT total score trials $1-5$ & $-1.35 \pm 1.35$ & $-0.34 \pm 1.33$ & $-0.81 \pm 1.19$ & $-5.223^{a}$ & $<\mathbf{0 . 0 0 1}^{\mathrm{a}}$ & $-1.964^{\mathrm{a}}$ & $0.061^{\mathrm{a}}$ & $2.111^{\mathrm{a}}$ & $0.045^{\mathrm{a}}$ \\
\hline CVLT long delay free recall II & $-1.09 \pm 1.04$ & $-0.74 \pm 1.17$ & $-0.94 \pm 1.09$ & $-2.486^{\mathrm{a}}$ & $0.020^{\mathrm{a}}$ & $0.868^{\mathrm{a}}$ & $0.395^{\mathrm{a}}$ & $1.594^{\mathrm{a}}$ & $0.124^{\mathrm{a}}$ \\
\hline ROCFT delayed recall & $0.13 \pm 0.93$ & $0.65 \pm 0.96$ & $0.40 \pm 0.71$ & $-3.482^{\mathrm{a}}$ & $0.002^{\mathrm{a}}$ & $-2.088^{\mathrm{a}}$ & $0.048^{\mathrm{a}}$ & $-1.588^{b}$ & $0.112^{\mathrm{b}}$ \\
\hline Physical activity & $n=26$ & $n=26$ & $n=24$ & & & & & & \\
\hline CVLT total score trials $1-5$ & $-1.00 \pm 1.20$ & $-0.81 \pm 1.30$ & $-0.59 \pm 1.66$ & $-1.261^{\mathrm{a}}$ & $0.219^{\mathrm{a}}$ & $-1.130^{\mathrm{b}}$ & $0.259^{\mathrm{b}}$ & $-0.373^{\mathrm{b}}$ & $0.709^{\mathrm{b}}$ \\
\hline CVLT long delay free recall II & $-1.22 \pm 1.00$ & $-0.75 \pm 1.10$ & $-0.69 \pm 1.44$ & $-3.477^{b}$ & $\mathbf{0 . 0 0 1}^{\mathrm{b}}$ & $-2.693^{a}$ & $0.013^{\mathrm{a}}$ & $-0.308^{b}$ & $0.758^{\mathrm{b}}$ \\
\hline ROCFT delayed recall & $0.35 \pm 1.16$ & $0.28 \pm 0.89$ & $0.21 \pm 0.78$ & $0.173^{\mathrm{a}}$ & $0.864^{\mathrm{a}}$ & $0.343^{\mathrm{a}}$ & $0.735^{\mathrm{a}}$ & $-1.049^{b}$ & $0.294^{\mathrm{b}}$ \\
\hline
\end{tabular}

Data are given in mean \pm standard deviation; significant results after Bonferroni correction are in bold

CVLT California Verbal Learning Test, ROCFT Rey-Osterrieth Complex Figure Test

${ }^{a}$ dependent $t$ test for paired samples

${ }^{\mathrm{b}}$ Wilcoxon test

significant interaction effect is driven by significant verbal and nonverbal memory improvement of the CT group from baseline to 6 months follow-up assessment while after 12 months the test performance declines. The largest CT improvement was demonstrated for the CVLT total score trials 1-5, a marker for the multidimensional construct of verbal learning. Remarkably, a comparable word list learning score turned out to be the most sensitive memory score for detecting memory dysfunction and cognitive impairment in PD-MCI patients [50], indicating that $\mathrm{CT}$ is enhancing highly vulnerable memory functions. Memory functions as primary outcome were expected to improve as the NEUROvitalis program includes training sessions focusing on the memory domain. Moreover, an enhancement in memory functioning after $\mathrm{CT}$ could be shown in previous PD studies $[13,51,52]$, however, these studies examined the training effect immediately after intervention. Also Alloni et al. [53] demonstrated significant memory improvement immediately after $\mathrm{CT}$ while six months after training, the improvement remained for one out of three memory test variables. Notably, in our study, the CT group did not benefit shortly after intervention regarding memory functioning, but only on the 6 months follow-up assessment. This result is consistent with a study from Lawrence et al. [54] who could show a significant verbal memory improvement 12 weeks after $\mathrm{CT}$ while immediately after $\mathrm{CT}$ this effect did not reach significance. One possible explanation for the delayed effect could be that CT contributes to the development of cognitive strategies what first results in an enhancement of executive functioning (as we found in our study immediately after training, see Kalbe et al. [15]) and is later transferred to memory performance. An argument for this hypothesis is the high strategic load of the CVLT due to the possibility of semantic clustering. Therefore, an influence of executive control on CVLT performance was demonstrated for patients with PD [55], PD dementia [56], mixed neurological patients [57], and older 
CVLT: total score trials $1-5$

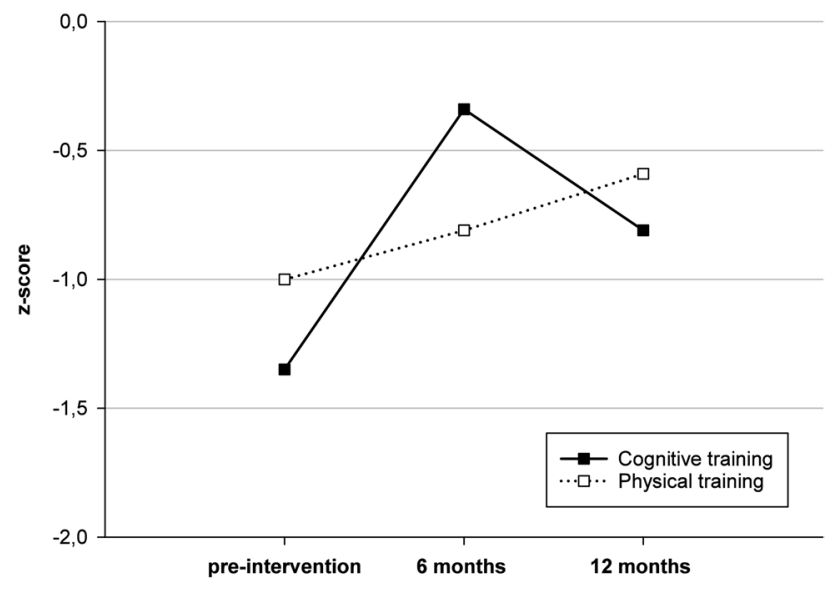

CVLT: long delay free recall II

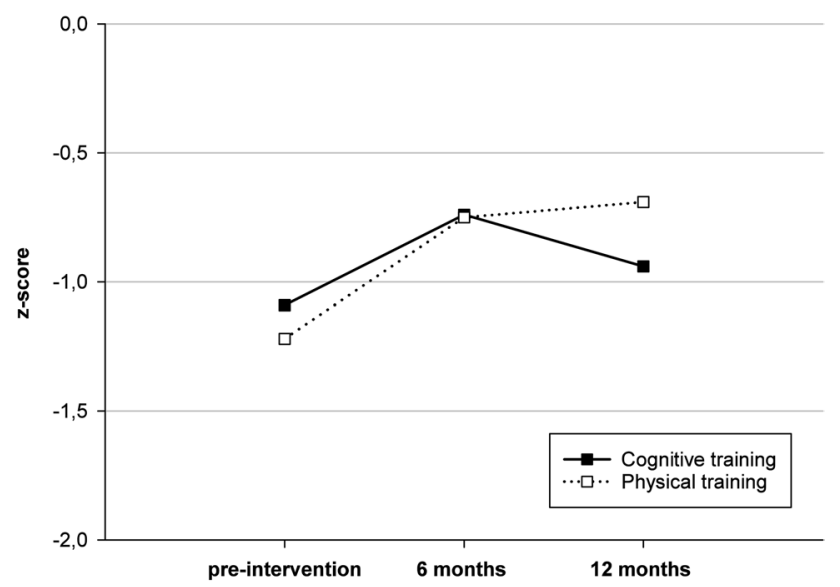

ROCFT: delayed recall

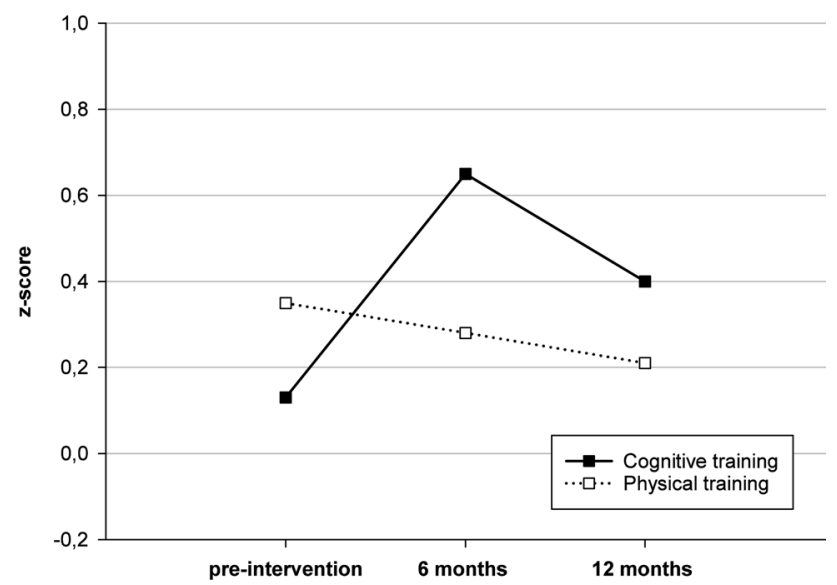

Fig. 1 Memory domain $z$-scores pre-intervention and at 6 and 12 months follow-up assessments for both training groups adults with suspected dementia [58]. Moreover, Alexander et al. [59] showed that patients with frontal lesions have difficulties in the CVLT due to poor implementation of a strategy of subjective organization. This explanation may be also applicable to the ROCFT, even though previous studies mainly focused on executive components of the copy condition and few studies provided inconsistent results regarding a strategic load of the recall condition [60,61]. Test-retest effects must also be considered as an explanation for the delayed memory improvement as at baseline assessment and 6 months follow-up assessment the same test version was used while immediately after intervention and at 12 months follow-up assessment a parallel version was conducted. However, there are two arguments against this suggestion. First, we found a significant time $\times$ group interaction effects while a test-retest effect would affect both groups. Second, there are no relevant mean $z$-score differences between postintervention assessment (results reported by Kalbe et al. [15]) and 12 months follow-up for CVLT total score (CT: $p=0.638$, PT: $p=0.148)$ and ROCFT delayed recall (CT: $p=0.271$, PT: $p=0.957)$ in either group, although the same test version was used in these assessments.

Regarding executive functions, the pre-post analyses showed a significant enhancement immediately after the training in the CT group compared to the PT group [15], however, after 6 and 12 months these results did not longer remain evident. Similar results for PD patients were found in the studies from Lawrence et al. [54] and Alloni et al. [53] in which training effects in executive functioning were significant immediately after CT, but mostly not at followup assessment (12 and 24 weeks, respectively). Similarly, in MCI patients without PD it has been demonstrated that CT impact is strong in the short-term, but not always strong enough to maintain efficient functioning in the long-term [62]. Especially with regard to the training effort (for both patients and clinical personal), future studies must examine how training effects can be preserved in the long-term. One possible method may be the conduction of further training sessions periodically after the main intervention (so-called "booster training") for refreshing the strategies learned. Also, continuous home exercises could prevent from a detraining effect over time.

The regression analyses did not reveal a significant model for predicting memory improvement after 6 months, although memory was the only domain in which significant improvements of the $\mathrm{CT}$ group could be demonstrated. Therefore, memory enhancement after CT could not be predicted by means of baseline score, age, sex, education level, motor status (UPDRS III), LEDD, or ApoE4 state, indicating that $\mathrm{CT}$ was comparably effective in all patients regardless of specific sociodemographic or disease-related characteristics. For executive functioning and the cognitive and non-cognitive secondary outcome 
variables, the respective baseline level turned out as main predictor for training gain in almost all cases, more precisely, lower baseline levels were predictive for CT responsiveness in the respective domain. This is in line with the short-term results of our study as lower baseline cognitive levels turned out to be the main predictor for training improvement directly after intervention [15]. Additional, higher respective lower age, female respective male sex, higher education level, lower baseline motor status, lower baseline LEDD, and positive respective negative ApoE4 status predicted training gains after 6 or 12 months in the CT group for selected outcomes. Previous PD studies detected lower baseline scores [12, 14], higher global cognitive status [11], higher fluid intelligence and higher self-efficacy expectancy [14], MCI diagnosis [13], higher educational level [11, 14], longer [10] or shorter disease duration [11], younger age [14], and younger age at PD diagnosis [10] as predictive for enhancements in cognitive functions immediately or 3 months after CT. These inconsistent results may be explained by study-specific differences (e.g., sample size and heterogeneity, cognitive tests used), but may also indicate the challenge of predicting CT responsiveness in cognitively impaired PD patients. In our study, the prediction results of the CT group were comparable to those of the PT group as in both groups a lower cognitive baseline level turned out as the main predictor for training responsiveness after 6 and 12 months. Therefore, a low specificity of the predictions for the type of interventional training is assumed. While the randomization procedure minimized the risk of a regression-tothe-mean effect [63], the predictive character of baseline level in both intervention groups may be explained by unspecific test-retest effects. In conclusion, CT can be recommended in PD-MCI patients irrespective of cognitive, educational or motor level, sex, medication characteristics, and ApoE4 status.

There are a few limitations to our study. First, due to recruitment difficulties, the a priori calculated sample size to achieve $80 \%$ power for detecting medium effect sizes was missed. However, as we found significant results, the risk of an underpowered study not being able to detect significant effects was not realized in our study. Second, the persons who carried out the diagnostic assessments were blinded regarding the intervention type, but the blinding was not complete as some patients reported details of intervention despite appropriate instructions. However, blinding is a general challenge in non-pharmacological studies. Third, the study did not include a passive control group what may restrict the clinical relevance as a physical activity training does not reflect clinical routine. However, the active control group is also a strength of our study because the significant effects cannot be attributed to unspecific effects due to the attention which is given to the patients during the training sessions. Nevertheless, future studies with an active and a passive control group should be carried out. Another strength of our study is that it is one of the first RCTs examining long-term effects of CT and its predictors for long-term responsiveness in PD-MCI.

\section{Conclusions}

In summary, this study provides Class 1 evidence that multidomain group CT enhances memory functions (but not executive functions) in PD-MCI patients in the long-term. The previously reported results of improvements in executive functioning immediately after $\mathrm{CT}$ could be extended by a delayed verbal and nonverbal memory improvement 6 months after intervention. Therefore, CT is an effective treatment of memory and executive functions in PD-MCI. No significant predictors could be detected for memory training gain indicating that $\mathrm{CT}$ is useful for PD patients unrelated to sociodemographic or disease-related characteristics.

Supplementary Information The online version contains supplementary material available at https://doi.org/10.1007/s00415-021-10568-9.

Funding Open Access funding enabled and organized by Projekt DEAL. This study was partly supported by a grant from the ParkinsonFonds Germany. Design of the database was supported by the German Centre for Neurodegenerative diseases (DZNE) e.V.

\section{Declarations}

Conflict of interest NS has received grants from the German Federal Ministry of Education and Research. DB has received honoraria from AbbVie, Biogen, BIAL, UCB Pharma GmbH Zambon, and Desitin and grants from Deutsche Forschungsgemeinschaft (DFG), German Parkinson's Disease Association (dPV), BMBF, Parkinson Fonds Deutschland gGmbH, UCB Pharma GmbH, EU, Novartis Pharma $\mathrm{GmbH}$, Lundbeck, and Damp foundation. She serves as a consultant for Biogen, BIAL, UCB Pharma GmbH, and Zambon. CSchl received funding from the Coppenrath-Foundation, the Parkinson Fonds Germany and honoraria from AbbVie, Wiesbaden, Germany. AKF has received grants from the German Parkinson Society and the German Alzheimer's Society, as well as honoraria from ProLog Wissen GmbH, Cologne, Germany, pro audito Switzerland, Zürich, Switzerland, Seminar- und Fortbildungszentrum Rheine, Germany, and LOGOMANIA, Fendt \& Sax GbR, Munich, Germany. AFK is author of the cognitive training program NEUROvitalis but receives no corresponding honoraria. LW has received honoraria from Meda, Boehringer, Cephalon Pharma, TEVA, Desitin, AbbVie St. Jude Medical/Abbott, and Medtronic and grants from HHU Düsseldorf, DFG Forschergruppe (FOR 1328), ERANET-Neuron/BMBF (TYMON 01EW141), German Parkinson's Disease Association (dPV), Parkinson Fonds Germany, and Hilde Ulrichs Stiftung für Parkinsonforschung. ILS has received grants from International Parkinson Fonds (Deutschland) GmbH (IPD), Johnson \& Johnson, European Commission, H2020-TWINN-2015, grants from Michael J. Fox Foundation outside the submitted work. CE has received grants from the German 
Research Foundation (KFO219, TP 10) and the Medical Faculty of the Philipps University Marburg, Germany, and the German Ministry of Education and Research and honoraria from AbbVie, Wiesbaden, Germany; UCB, Monheim, Germany; Daiichi Sankyo, Munich, Germany; Medtronic, Meerbusch, Germany; Bayer Vital, Leverkusen, Germany; and Bial, Morfelden-Walldorf, Germany. EK has received grants from the German Ministry of Education and Research, ParkinsonFonds Deutschland gGmbH, the German Parkinson Society, the German Alzheimer's Society; honoraria from: Oticon GmbH, Hamburg, Germany; Lilly Pharma GmbH, Bad Homburg, Germany; Bernafon AG, Bern, Switzerland; Desitin GmbH, Hamburg, Germany. EK is author of the cognitive training program NEUROvitalis but receives no corresponding honoraria. KW serves as a consultant for BIAL. IT, AO, KD, SE, PS, and CSchu declare that there are no conflicts of interest.

Ethical standards The authors assert that all procedures contributing to this work comply with the ethical standards of the relevant national and institutional committees on human experimentation and with the Helsinki Declaration of 1975, as revised in 2013. All persons gave their informed consent prior to their inclusion in the study.

Open Access This article is licensed under a Creative Commons Attribution 4.0 International License, which permits use, sharing, adaptation, distribution and reproduction in any medium or format, as long as you give appropriate credit to the original author(s) and the source, provide a link to the Creative Commons licence, and indicate if changes were made. The images or other third party material in this article are included in the article's Creative Commons licence, unless indicated otherwise in a credit line to the material. If material is not included in the article's Creative Commons licence and your intended use is not permitted by statutory regulation or exceeds the permitted use, you will need to obtain permission directly from the copyright holder. To view a copy of this licence, visit http://creativecommons.org/licenses/by/4.0/.

\section{References}

1. Monastero R, Cicero CE, Baschi R, Davì M, Luca A, Restivo V et al (2018) Mild cognitive impairment in Parkinson's disease. The Parkinson's disease cognitive study (PACOS). J Neurol 265:1050-1058. https://doi.org/10.1007/s00415-018-8800-4

2. Wiesli D, Meyer A, Fuhr P, Gschwandtner U (2017) Influence of Mild cognitive impairment, depression, and anxiety on the quality of life of patients with Parkinson disease. Dement Geriatr Cogn Dis Extra 7:297-308. https://doi.org/10.1159/000478849

3. de Lau LML, Verbaan D, Marinus J, van Hilten JJ (2014) Survival in Parkinson's disease. Relation with motor and non-motor features. Parkinsonism Relat Disord 20:613-616. https://doi.org/ 10.1016/j.parkreldis.2014.02.030

4. Rolinski M, Fox C, Maidment I, McShane R (2012) Cholinesterase inhibitors for dementia with Lewy bodies, Parkinson's disease dementia and cognitive impairment in Parkinson's disease. Cochrane Database Syst Rev. https://doi.org/10.1002/14651858. CD006504.pub2

5. McShane R, Westby MJ, Roberts E, Minakaran N, Schneider L, Farrimond LE et al (2019) Memantine for dementia. Cochrane Database Syst Rev 3:CD003154. https://doi.org/10.1002/14651 858.CD003154.pub6

6. Leung IHK, Walton CC, Hallock H, Lewis SJG, Valenzuela M, Lampit A (2015) Cognitive training in Parkinson disease. A systematic review and meta-analysis. Neurology 85:1843-1851. https://doi.org/10.1212/WNL.0000000000002145
7. Lawrence BJ, Gasson N, Bucks RS, Troeung L, Loftus AM (2017) Cognitive training and noninvasive brain stimulation for cognition in Parkinson's disease: a meta-analysis. Neurorehabil Neural Repair 31:597-608. https://doi.org/10.1177/1545968317712468

8. Pupíková M, Rektorová I (2020) Non-pharmacological management of cognitive impairment in Parkinson's disease. J Neural Transm 127:799-820. https://doi.org/10.1007/ s00702-019-02113-w

9. Orgeta V, McDonald KR, Poliakoff E, Hindle JV, Clare L, Leroi I (2020) Cognitive training interventions for dementia and mild cognitive impairment in Parkinson's disease. Cochrane Database Syst Rev. https://doi.org/10.1002/14651858.CD011961.pub2

10. Edwards JD, Hauser RA, O'Connor ML, Valdés EG, Zesiewicz TA, Uc EY (2013) Randomized trial of cognitive speed of processing training in Parkinson disease. Neurology 81:1284-1290. https://doi.org/10.1212/WNL.0b013e3182a823ba

11. Fellman D, Salmi J, Ritakallio L, Ellfolk U, Rinne JO, Laine M (2020) Training working memory updating in Parkinson's disease. A randomised controlled trial. Neuropsychol Rehabil 30:673-708. https://doi.org/10.1080/09602011.2018.1489860

12. Zimmermann R, Gschwandtner U, Benz N, Hatz F, Schindler C, Taub E et al (2014) Cognitive training in Parkinson disease. Cognition-specific vs nonspecific computer training. Neurology 82:1219-1226. https://doi.org/10.1212/WNL.0000000000000287

13. París AP, Saleta HG, de La Cruz Crespo Maraver M, Silvestre E, Freixa MG, Torrellas CP et al (2011) Blind randomized controlled study of the efficacy of cognitive training in Parkinson's disease. Mov Disord 26:1251-1258. https://doi.org/10.1002/mds.23688

14. Ophey A, Rehberg S, Giehl K, Eggers C, Reker P, van Eimeren T et al (2021) Predicting working memory training responsiveness in Parkinson's disease: both "System Hardware" and room for improvement are needed. Neurorehabil Neural Repair 35:117130. https://doi.org/10.1177/1545968320981956

15. Kalbe E, Folkerts A-K, Ophey A, Eggers C, Elben S, Dimenshteyn K et al (2020) Enhancement of executive functions but not memory by multidomain group cognitive training in patients with Parkinson's disease and mild cognitive impairment: a multicenter randomized controlled trial. Parkinson's Disease 2020:1-15. https://doi.org/10.1155/2020/4068706

16. Hughes AJ, Daniel SE, Kilford L, Lees AJ (1992) Accuracy of clinical diagnosis of idiopathic Parkinson's disease: a clinicopathological study of 100 cases. J Neurol Neurosurg Psychiatr 55:181-184. https://doi.org/10.1136/jnnp.55.3.181

17. Litvan I, Goldman JG, Tröster AI, Schmand BA, Weintraub D, Petersen RC et al (2012) Diagnostic criteria for mild cognitive impairment in Parkinson's disease: movement disorder society task force guidelines. Mov Disord 27:349-356. https://doi.org/ $10.1002 / \mathrm{mds} .24893$

18. Jessen F, Wolfsgruber S, Wiese B, Bickel H, Mösch E, Kaduszkiewicz $\mathrm{H}$ et al (2014) AD dementia risk in late MCI, in early MCI, and in subjective memory impairment. Alzheimer's Dementia 10:76-83. https://doi.org/10.1016/j.jalz.2012.09.017

19. Nasreddine ZS, Phillips NA, Bédirian V, Charbonneau S, Whitehead V, Collin I et al (2005) The montreal cognitive assessment, MoCA: a brief screening tool for mild cognitive impairment. J Am Geriatr Soc 53:695-699. https://doi.org/10.1111/j.1532-5415. 2005.53221.x

20. Emre M, Aarsland D, Brown R, Burn DJ, Duyckaerts C, Mizuno $Y$ et al (2007) Clinical diagnostic criteria for dementia associated with Parkinson's disease. Mov Disord 22:1689-1707. https://doi. org/10.1002/mds.21507

21. Dubois B, Burn D, Goetz C, Aarsland D, Brown RG, Broe GA et al (2007) Diagnostic procedures for Parkinson's disease dementia: recommendations from the movement disorder society task force. Mov Disord 22:2314-2324. https://doi.org/10.1002/mds. 21844 
22. Beck AT, Steer RA, Brown GK (1996) Manual for the Beck depression inventory-II. Psychological Corporation, San Antonio, TX, USA

23. Baller G, Kalbe E, Kaesberg S, Kessler J (2009) Neurovitalis: ein neuropsychologisches Gruppenprogramm zur Förderung der geistigen Leistungsfähigkeit. ProLog, Cologne, Germany

24. Baller G, Folkerts AK, Kessler J, Kalbe E (2021) NEUROvitalis Parkinson: ein wissenschaftlich fundiertes Gruppenprogramm zur Förderung der geistigen Leistungsfähigkeit bei Morbus Parkinson Patienten. ProLog, Cologne, Germany

25. Niemann H, Sturm W, Thöne-Otto A, Willmes K (2008) CVLT. California Verbal Learning Test. Deutsche Adaptation. Pearson, Frankfurt am Main

26. Strauss E, Sherman EMS, Spreen O (2006) Compendium of neuropsychological tests: administration, norms and commentary. Oxford University Press, New York, NY

27. Aschenbrenner S, Tucha O, Lange KW (2000) Regensburger Wortflüssigkeits-Test: RWT. Hogrefe, Göttingen

28. Schretlen DJ (2011) M-WCST, Modified Wisconsin Card Sorting Test. Psychological Assessment Resources, Lutz, FL

29. Wilson BA, Emslie H, Evans JJ, Alderman N, Burgess PW (1991) Behavioural Assessment of the Dysexecutive Syndrome (BADS). Pearson, London

30. Brickenkamp R, Schmidt-Atzert L, Liepmann D (2010) Test d2 Revision. Aufmerksamkeits- und Konzentrationstest. Hogrefe, Göttingen

31. Wechsler D (1997) Wechsler adult intelligence scale — third edition (WAIS-III). Pearson, London

32. Benton AL, Sivan AB, Hamsher K, Varney NR, Spreen O (1983) Benton judgement of line orientation. Psychological Assessment Resources, Lutz, FL

33. Morris JC, Heyman A, Mohs RC, Hughes JP, van Belle G, Fillenbaum $\mathrm{G}$ et al (1989) The consortium to establish a registry for Alzheimer's disease (CERAD). Part I. Clinical and neuropsychological assessment of Alzheimer's disease. Neurology 39:1159-1165. https://doi.org/10.1212/wnl.39.9.1159

34. Kalbe E, Reinhold N, Ender U, Kessler J (2010) ACL-AphasieCheck-Liste. ProLog, Cologne

35. Erzigkeit H, Lehfeld H (2010) Bayer ADL-Skala. Eine Skala zur Erfassung von Beeinträchtigungen der Alltagskompetenz bei älteren Patienten mit Einbußen der kognitiven Leistungsfähigkeit. Pearson, Frankfurt am Main

36. Washburn RA, Smith KW, Jette AM, Janney CA (1993) The physical activity scale for the elderly (PASE): development and evaluation. J Clin Epidemiol 46:153-162. https://doi.org/10.1016/08954356(93)90053-4

37. Jenkinson C, Fitzpatrick R, Peto V, Greenhall R, Hyman N (1997) The Parkinson's disease questionnaire (PDQ-39). Development and validation of a Parkinson's disease summary index score. Age Ageing 26:353-357. https://doi.org/10.1093/ageing/26.5.353

38. Zimmermann P, Merser C, Poser U, Sedelmeier P (1991) Ein Fragebogen erlebter Defizite der Aufmerksamkeit (FEDA). University Institute of Psychology, Freiburg

39. Fahn S, Elton RL, Members of the UPDRS development committee (1987) Unified Parkinson's disease rating scale. In: Fahn S, Marsden CD, Calne DB et al (eds) Recent developments in Parkinson's disease, vol 2. Macmillan Health Care Information. Florham Park, NJ, pp 153-164

40. Giladi N, Shabtai H, Simon ES, Biran S, Tal J, Korczyn AD (2000) Construction of freezing of gait questionnaire for patients with Parkinsonism. Parkinsonism Relat Disord 6:165-170. https://doi.org/ 10.1016/s1353-8020(99)00062-0

41. Cohen J (1977) Statistical power analysis for the behavioral sciences. Academic Press, New York, NY

42. Langbaum JBS, Rebok GW, Bandeen-Roche K, Carlson MC (2009) Predicting memory training response patterns: results from
ACTIVE. J Gerontol B Psychol Sci Soc Sci 64:14-23. https://doi. org/10.1093/geronb/gbn026

43. Jean L, Simard M, Wiederkehr S, Bergeron M-E, Turgeon Y, Hudon $\mathrm{C}$ et al (2010) Efficacy of a cognitive training programme for mild cognitive impairment: results of a randomised controlled study. Neuropsychol Rehabil 20:377-405. https://doi.org/10.1080/0960201090 3343012

44. Whitlock LA, McLaughlin AC, Allaire JC (2012) Individual differences in response to cognitive training: using a multi-modal, attentionally demanding game-based intervention for older adults. Comput Hum Behav 28:1091-1096. https://doi.org/10.1016/j.chb. 2012.01.012

45. Fairchild JK, Friedman L, Rosen AC, Yesavage JA (2013) Which older adults maintain benefit from cognitive training? Use of signal detection methods to identify long-term treatment gains. Int Psychogeriatr 25:607-616. https://doi.org/10.1017/S1041610212002049

46. Rebok GW, Langbaum JBS, Jones RN, Gross AL, Parisi JM, Spira AP et al (2013) Memory training in the ACTIVE study: how much is needed and who benefits? J Aging Health 25:21S-42S. https://doi. org/10.1177/0898264312461937

47. Rahe J, Becker J, Fink GR, Kessler J, Kukolja J, Rahn A et al (2015) Cognitive training with and without additional physical activity in healthy older adults: cognitive effects, neurobiological mechanisms, and prediction of training success. Front Aging Neurosci 7:187. https://doi.org/10.3389/fnagi.2015.00187

48. Roheger M, Kalbe E, Corbett A, Brooker H, Ballard C (2020) Predictors of changes after reasoning training in healthy adults. Brain Behav 10:e01861. https://doi.org/10.1002/brb3.1861

49. Roheger M, Meyer J, Kessler J, Kalbe E (2020) Predicting short- and long-term cognitive training success in healthy older adults: who benefits? Neuropsychol Dev Cogn B Aging Neuropsychol Cogn 27:351-369. https://doi.org/10.1080/13825585.2019.1617396

50. Kalbe E, Rehberg SP, Heber I, Kronenbuerger M, Schulz JB, Storch A et al (2016) Subtypes of mild cognitive impairment in patients with Parkinson's disease: evidence from the LANDSCAPE study. J Neurol Neurosurg Psychiatry 87:1099-1105. https://doi.org/10. 1136/jnnp-2016-313838

51. Peña J, Ibarretxe-Bilbao N, García-Gorostiaga I, Gomez-Beldarrain MA, Díez-Cirarda M, Ojeda N (2014) Improving functional disability and cognition in Parkinson disease: randomized controlled trial. Neurology 83:2167-2174. https://doi.org/10.1212/WNL.00000 00000001043

52. Petrelli A, Kaesberg S, Barbe MT, Timmermann L, Fink GR, Kessler J et al (2014) Effects of cognitive training in Parkinson's disease: a randomized controlled trial. Parkinsonism Relat Disord 20:11961202. https://doi.org/10.1016/j.parkreldis.2014.08.023

53. Alloni A, Quaglini S, Panzarasa S, Sinforiani E, Bernini S (2018) Evaluation of an ontology-based system for computerized cognitive rehabilitation. Int J Med Inform 115:64-72. https://doi.org/10. 1016/j.jimedinf.2018.04.005

54. Lawrence BJ, Gasson N, Johnson AR, Booth L, Loftus AM (2018) Cognitive training and transcranial direct current stimulation for mild cognitive impairment in Parkinson's disease: a randomized controlled trial. Parkinson's Disease 2018:4318475. https://doi.org/ $10.1155 / 2018 / 4318475$

55. Higginson CI, King DS, Levine D, Wheelock VL, Khamphay NO, Sigvardt KA (2003) The relationship between executive function and verbal memory in Parkinson's disease. Brain Cogn 52:343-352. https://doi.org/10.1016/S0278-2626(03)00180-5

56. O'Brien TJ, Wadley V, Nicholas AP, Stover NP, Watts R, Griffith HR (2009) The contribution of executive control on verbal-learning impairment in patients with Parkinson's disease with dementia and Alzheimer's disease. Arch Clin Neuropsychol 24:237-244. https:// doi.org/10.1093/arclin/acp029

57. Hill BD, Alosco M, Bauer L, Tremont G (2012) The relation of executive functioning to CVLT-II learning, memory, and process 
indexes. Appl Neuropsychol Adult 19:198-206. https://doi.org/10. 1080/09084282.2011.643960

58. Brooks BL, Weaver LE, Scialfa CT (2006) Does impaired executive functioning differentially impact verbal memory measures in older adults with suspected dementia? Clin Neuropsychol 20:230-242. https://doi.org/10.1080/13854040590947461

59. Alexander MP, Stuss DT, Fansabedian N (2003) California Verbal Learning Test: performance by patients with focal frontal and nonfrontal lesions. Brain 126:1493-1503. https://doi.org/10.1093/brain/ awg 128

60. Janowsky JS, Thomas-Thrapp LJ (1993) Complex figure recall in the elderly: a deficit in memory or constructional strategy? J Clin Exp Neuropsychol 15:159-169. https://doi.org/10.1080/0168863930 8402554
61. Westervelt $\mathrm{H}$ (2000) The impact of organizational strategy on recall of the Rey-Osterrieth complex figure. Arch Clin Neuropsychol 15:684. https://doi.org/10.1016/S0887-6177(00)80060-8

62. Moro V, Condoleo MT, Valbusa V, Broggio E, Moretto G, Gambina $\mathrm{G}$ (2015) Cognitive stimulation of executive functions in mild cognitive impairment: specific efficacy and impact in memory. Am J Alzheimers Dis Other Demen 30:153-164. https://doi.org/10.1177/ 1533317514539542

63. Yudkin PL, Stratton IM (1996) How to deal with regression to the mean in intervention studies. The Lancet 347:241-243. https://doi. org/10.1016/S0140-6736(96)90410-9

\section{Authors and Affiliations}

\section{Nele Schmidt ${ }^{1,2} \cdot$ Inken Tödt $^{2} \cdot$ Daniela Berg ${ }^{2} \cdot$ Christian Schlenstedt $^{2} \cdot$ Ann-Kristin Folkerts $^{3} \cdot$ Anja Ophey $^{3}$. Karina Dimenshteyn ${ }^{4} \cdot$ Saskia Elben $^{4} \cdot$ Lars Wojtecki $^{4} \cdot$ Inga Liepelt-Scarfone $^{5,6}$. Claudia Schulte ${ }^{5}$. Patricia Sulzer ${ }^{5}$. Carsten Eggers $^{7,8} \cdot$ Elke Kalbe $^{3} \cdot$ Karsten Witt $^{1,9}$}

1 Department of Neurology, University Oldenburg, Steinweg 13-17, 26122 Oldenburg, Germany

2 Department of Neurology, University Hospital Schleswig-Holstein, Christian-Albrechts-University, Kiel, Germany

3 Medical Psychology, Neuropsychology and Gender Studies, Center for Neuropsychological Diagnostics and Interventions (CeNDI), Faculty of Medicine and University Hospital Cologne, University of Cologne, Cologne, Germany

4 Department of Neurology, Center for Movement Disorders and Neuromodulation and Institute of Clinical Neuroscience and Medical Psychology, Medical Faculty, Heinrich-Heine-University Duesseldorf, Duesseldorf, Germany

5 Department of Neurodegenerative Diseases, German Center for Neurodegenerative Diseases (DZNE) and Hertie Institute for Clinical Brain Research, University of Tuebingen, Tuebingen, Germany

6 IB Hochschule Für Gesundheit Und Soziales, Stuttgart, Germany

7 Department of Neurology, University Hospital of Marburg, Center for Mind, Brain and Behavior (CMBB), Universities Marburg and Giessen, Marburg, Germany

8 Department of Neurology, Faculty of Medicine and University Hospital Cologne, University of Cologne, Cologne, Germany

9 Research Center Neurosensory Science, Carl von Ossietzky University Oldenburg, Oldenburg, Germany 